\title{
EL «ESTILO DE LA CARNE» EN MAIKRUX Y FALETE: FEMINIDAD, HUMOR Y AGENCIA
}

\author{
AMAia Álvarez URIA \\ Universidad del País Vasco \\ Raquel (Lucas) Platero MÉNDeZ \\ Universidad Rey Juan Carlos \\ MARÍA ROSÓN VILLENA \\ Universidad Autónoma de Madrid
}

Recibido: 15/09/2014

Aceptado: 24/11/2014

\section{Resumen}

Maikruz y Falete son dos personajes televisivos que forman parte de la cultura popular vasca y española y que performan identidades de género no hegemónicas, pues encarnan feminidades fuertes a pesar de haber sido asignados como varones en el nacimiento. Nuestro análisis atiende a cómo el humor y lo vernáculo más que desactivar su posible potencialidad política, los convierte en una parte del imaginario cultural de «posibilidad» y agencia. Esto es posible no sólo por lo que Maikrux y Falete «son» sino por que la audiencia puede reapropiarse de ciertos aspectos placenteros que ellos transmiten, para empoderarse y realizar identificaciones plurales y complejas.

Palabras clave: humor, queer, señoras, folclóricas, crip, recepción

\begin{abstract}
Maikrux and Falete are two TV figures which form part of Basque and Spanish popular culture. Both of them perform non-hegemonic gender identities, embodying strong femininities despite the fact they were assigned as male at birth. Our analysis deals with humour and the vernacular, in which we highlight that instead of deactivating their possible political potentiality, their role in the cultural imagination allows "possibility» and agency. This is possible not only because of what Maikrux and Falete
\end{abstract}


«are» but rather because the audience can reappropriate certain pleasures that they embody, empowering the audiences with complex and plural identifications.

Keywords: humour, queer, señoras/ladies, folcloricas, crip, reception 


\section{Introducción}

¿A qué se debe el éxito mediático de Falete y Maikrux?, ¿porqué baten records de audiencia?, ¿qué placeres nos provoca verles en la televisión? Nuestro objetivo en este artículo es proporcionar algunas reflexiones que parten del estudio de dos personas que encarnan feminidades fuertes, presentes en la cultura popular vasca y española, y que fueron asignados al nacimiento como sujetos varones ${ }^{1}$. Éstos son Maikrux, un personaje de ficción interpretado por el actor Anjel Alkain en el programa televisivo de humor Kontuz atsuak!, de ETB1, y el cantante de copla y flamenco Falete, también conocido por su participación en programas de televisión como Splash! Famosos al agua, de Antena 3. La pregunta clave que ha guiado nuestra investigación es el planteamiento de por qué estas personas, que podríamos considerar como disidentes de género son, en principio, aceptados por las audiencias televisivas vasca y española contemporáneas sin que su «gender trouble» suponga necesariamente un cuestionamiento de las normas de género hegemónicas. Más que pensar que Maikrux o Falete funcionan socialmente a la manera de «freaks», permitiendo una vía de escape basada en el humor pero que desactiva las posibles implicaciones políticas, pensamos que tanto la cultura popular como el humor son dos lugares de posibilidad, que pueden llegar a transformarse en territorios abonados para las resistencias, basadas éstas fundamentalmente en el placer y la agencia que las audiencias pueden elaborar a partir de recepciones y/o identificaciones plurales y complejas.

Hemos organizado la discusión en cuatro epígrafes, donde abordamos el «estilo de la carne» o la performatividad de género en femenino que despliegan Maikrux y Falete, algunas notas sobre los protagonistas de este artículo, pasando a abordar la importancia del humor por herramienta para la agencia.

1. Este artículo es fruto de la mesa redonda «Feminidades impostadas» presentada por las autoras en el XV Congreso Internacional de Mujeres Filósofas, Alcalá de Henares (Madrid), 29 de junio de 2014. Este artículo se enmarca dentro de los siguientes proyectos de investigación I+D del Ministerio de Economía y Competitividad: «Colectivos en los márgenes: su exclusión por el derecho en tiempos de crisis (2013-2015)» (DER 2012-34320) $\mathrm{y}$ «La historia del arte en España: devenir, discursos y propuestas» (HAR 2012-32609). 
Seguidamente reflexionamos sobre algunas ideas culturales que han conformado los estereotipos de señoras y folclóricas, así como el legado cinematográfico donde vincular las experiencias que nos producen Maikrux y Falete, para terminar con las conclusiones, donde destacan algunas ideas principales: la necesidad de abrir el campo de estudio relativo de la cultura contemporánea, atendiendo a cierta parte de la cultura popular que promueve lógicas no binarias en relación al género, así como a la ausencia de este tipo de propuestas en nuestros contextos académicos, lo cual se traduce en la falta de participación en los debates internacionales.

\section{2. ¿Cómo estudiar «el estilo de la carne»?}

Antes de iniciar el análisis creemos importante introducir teóricamente algunos de nuestros planteamientos. Entendemos el cuerpo trascendiendo la clásica división occidental mente versus cuerpo, para hablar del continuum de la experiencia, algo ya presente en la filosofía de Baruch Spinoza y que ha sido retomado por las teorías del «giro afectivo $»^{2}$. Por feminidades entendemos maneras o estilos de habitar el cuerpo, que no necesariamente se delimitan a un sexo asignado en el nacimiento, una anatomía fija o una documentación oficial determinada. Fue Judith Butler en El género en disputa, quien interpretó el género como «estilos de la carne», «un "acto", por así decirlo, pero es al mismo tiempo intencional y performativo $»^{3}$. Estos actos se repiten constantemente, por ello para Butler, la construcción del género es una copia de una copia, una repetición sin original, incidiendo así en el carácter performativo, teatralizado o actuado, de toda identidad. Al fijarnos en Maikrux y Falete, en tanto que son sujetos mediáticos femeninos que encarnan ciertos «estilos de la carne», se podría entender que estamos introduciendo «una mirada sobre lo excepcional o lo minoritario»: nada más lejos de nuestra intención. Todas las personas producimos ciertas maneras de encarnar lo que entendemos como «género», «sexo» o «sexualidad», categorías que además, se presentan alineadas para producir una inscripción heterosexualizante de los sujetos. No sólo la feminidad «ha de ser propia» de las mujeres y la masculinidad «exclusiva» de los hombres, sino que han de ser concordantes con la asignación en el nacimiento, la socialización

2. Clough, Patricia (ed.). The Affective Turn: Theorizing the Social. Durham, Duke University Press, 2007. Para un excelente estado de la cuestión sobre este tema desde una perspectiva de género véase Medina DomeneCH, Rosa María. «Sentir la Historia. Propuestas para una agenda de investigación feminista en la historia de las emociones». Arenal. Revista de Historia de las Mujeres 19/1 (2012), pp. 161-199.

3. BUTLER, Judith. El género en disputa. El feminismo y la subversión de la identidad. Barcelona, Paidós, 2007, p. 271. 
y el reparto de roles sociales desiguales, dentro de un marco de relaciones heterosexistas. La elección de Falete y Maikrux como objeto de análisis tiene más que ver con el hecho de que ejemplifican cómo el humor puede ser una herramienta de agencia, tanto para las audiencias como para los protagonistas.

Por otra parte, tanto Maikrux como Falete se pueden entender como relativos al ámbito de la cultura popular, que es un concepto que entendemos siguiendo a Pierre Bourdieu ${ }^{4}$. En consecuencia, no nos detenemos tanto en las características del producto u objeto cultural, el propio Falete o de Maikrux, como en la forma de recibirlos. La recepción en la cultura popular se caracteriza por ser emocional, expresiva y corporal -por supuesto, feminizada-, mientras que en la cultura de élite es distanciada, intelectualizada y con desapego. En la academia del Estado español, la cultura popular se ha tendido a interpretar desde una perspectiva propia del marxismo clásico, que fue central en la oposición antifranquista, especialmente a través de las teorías de las industrias culturales desarrolladas por Theodor Adorno y Max Horkheimer ${ }^{5}$, en la cuales primaba el entendimiento del adoctrinamiento ideológico unidireccional, de arriba abajo, sobre todo en regímenes totalitarios.

Frente a ello, Jo Labanyi ${ }^{6}$ propone seguir el pensamiento gramsciano de hegemonía y contrahegemonía para el análisis cultural: frente a la unidireccionalidad, Antonio Gramsci entiende la cultura como un lugar de lucha entre una pluralidad de fuerzas, de grupos sociales entre sí heterogéneos y fragmentados, dominantes y subalternos, que pugnan por la hegemonía a través de la constante negociación y que se relacionan mediante el doble proceso de complicidad y resistencia. Incluso cuando las clases tradicionales son hegemónicas, «la necesidad de negociar el consentimiento mediante prácticas culturales les proporciona un espacio a las clases subalternas» ${ }^{7}$. Por tanto, el subalterno no es un sujeto pasivo y absolutamente manipulado culturalmente, sino, que dentro de sus circunstancias, es un sujeto con agencia, entendida como capacidad de acción y actuación. Estas ideas conectan directamente con el pensamiento de Walter Benjamin o Mikhail Bakthin, así como con las teorías poscoloniales, pues las identidades culturales se piensan como viajes de ida y vuelta, en los cuales los subalternos pueden, en un proceso de mímica y reciclado, apropiarse de aspectos

4. Bordieu, Pierre. La distinción. Criterio y bases sociales del gusto. Madrid, Taurus, 1998.

5. Adorno, Theodor W. y HORKHEIMER, Max: «La industria cultural. Ilustración como engaño de masas», en Dialéctica de la ilustración, Madrid, vol. 3, Akal, 2007, pp. 133-182.

6. LabanyI, Jo. «Gramsci and the Spanish Cultural Studies». Paragraph 22/1 (1999), pp. 95-113.

7. LABANYI, Jo. «Música, populismo y hegemonía en el cine del primer franquismo», en Luis Fernández Colorado y Pilar Couto Cantero (eds.): Cuadernos de la Academia. La herida de las sombras. El cine español de los años 40, núm. 9, 2001, p. 84. 
de la cultura dominante para sus propósitos tácticos. En consecuencia, el marco teórico gramsciano ayuda a entender la recepción de los productos culturales desde el punto de vista de la posible apropiación y resignificación por parte de los usuarios o espectadores según sus intereses, y no sólo desde la perspectiva del adoctrinamiento o manipulación propagandística de unos mensajes determinados y emitidos por parte del poder político, que son asumidos pasivamente.

Este tipo de aproximaciones son mucho más flexibles y permiten recuperar las experiencias relacionadas con la producción cultural desde la complejidad de la vida cotidiana, más allá de la consideración de los programas, las películas o los personajes como textos culturales, a través de los que los distintos poderes tratan de diseminar sus mensajes mediante mecanismos de adoctrinamiento y propaganda. Nos permite recuperar los placeres y emociones que las audiencias sienten cuando escuchan cantar a Falete o perciben la irreverencia de Maikrux al entrevistar a personajes famosos, pero especialmente nos remite a la capacidad para reelaborar y resignificar estas experiencias según sus intereses y su situación vital. También, nos ayuda a entender que la cultura proporciona experiencias multisensoriales (ver, escuchar, tocar, sentir ganas de reírse, imaginar, por ejemplo) en lugar de fijarnos únicamente en textos, imágenes o representaciones, que están más centradas en el ámbito de la mirada, entendida ésta desde el posicionamiento del control y el poder.

\section{Algunas notas sobre Maikrux y Falete}

A continuación introducimos brevemente a los dos protagonistas que abordamos en este artículo, Maikrux y Falete. Maikrux es el personaje cómico televisivo encarnado e interpretado por el actor Anjel Alkain, en el programa de humor Kontuz atsuak! (Cuidado con las viejas) de la televisión autonómica vasca ETB1. Anjel Alkain como Maikrux junto con Iñake Irastorza como Maikarmen, son dos señoras sin marido y jubiladas que protagonizaron «Gure atsuak» (nuestras viejas), en un sketch semanal dentro el programa de humor Wazemank (jvamonxs!), emitido entre 2005 y 2007. En el curso 2012/2013 esta pareja cómica volvió a la pantalla en un programa propio, el citado Kontuz atsuak!, con la intención de hacer un «Salvados con humor» ${ }^{8}$, y que en palabras de Maikrux: «Humor e información, esa es la clave de nuestro éxito» ${ }^{9}$. La palabra «atso(a)» o su variante dialectal «atsu(a)» significa en su primera acepción

8. URKIZU, Urtzi. «Finlandia' saioa desagertu ostean, 'Kontuz atsuak!' helduko da ETBlera». Berria (10-07-2012), p. 28.

9. MitXelEnA, Eñaut. «Herriak behar gaitu, bestela ez gintuzten hainbeste maiteko». Aizu! 376 (Abril de 2013), pp. 30-33. 
'mujer anciana' o 'vieja', en la segunda, 'parienta' o 'contraria', y en la tercera, 'tía' o 'chorba'. En varios dialectos de la lengua vasca, además, tiene cierta connotación negativa, por lo que resulta una palabra con una fuerte carga semántica la elegida para dar título y cuerpo al programa y a los personajes en cuestión.

Según el actor Anjel Alkain: «Siempre he sido un poco transgresor con el mundo del euskera, con el mundo de los bertsolaris y con todo aquello que sea cercano al mundo euskaldun (...) Vamos a reírnos un poco de lo que conocemos» ${ }^{10}$. Al describir a estas señoras, dice que: «Maikarmen y Maikrux pueden ser nuestras tías, vecinas o madres; son dos mujeres ocurrentes y peculiares, dos solteronas que han perdido la vergüenza al envejecer» ${ }^{11}$. Las mismas Maikrux y Maikarmen señalan que «el pueblo nos quiere» ${ }^{12}$. Y al responder Alkain cómo se siente al interpretar a una mujer se queja del tiempo necesario para maquillarse, la dificultad de encontrar zapatos de su tamaño y del dinero que ha gastado en cuchillas de afeitar ${ }^{13}$, aunque al mismo tiempo afirma que «a los hombres nos gusta hacer de mujer» ${ }^{14}$.

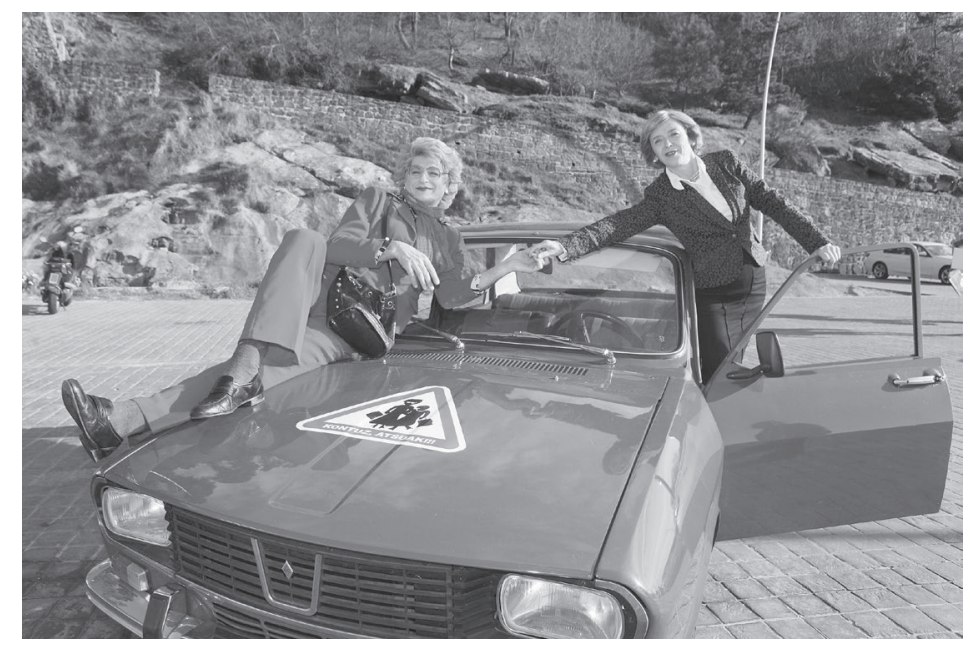

Foto 1. Foto de Maikrux y Maikarmen, «nuestras viejas». Revista Aizu! 376 (Abril de 2013), pp. 32. Fotógrafo Gorka Estrada.

10. LAKUNZA, Rosana. «Hay programas donde no hay intención de innovar: son demasiado cuadrados». Deia (19/09/2011), p. 66.

11. ETXEBERRIA, Idoia. «Earki gatxink!». Berria (27-01-2006), pp. 4 y 5.

12. MitXelena, Eñaut. Op. cit.

13. LASA, Iñaki. «Bizitzak ba al du zentzurik barrerik egin gabe ba?». Berria (06-01-2013), p. 36.

14. LoPEZ, Elisa. «¿Hacer de mujer? Pues sí, a los hombres nos gusta». Diario Vasco (0910-2011), p. 82 .

Feminismo/s 24, diciembre 2014, pp. 143-162 
Maikrux es una abuela vasca tradicional, que cuida mucho su imagen para mantener su estatus social respetable, y a la vez, participa activamente en la vida social entrevistando a personajes conocidos en la sociedad vasca, actuando como una solterona curiosa y desvergonzada, un sujeto heterosexual deseante, inteligente, está empoderada, es aventurera y tiene la complicidad de su compañera, Maikarmen: «Nosotras sí que somos unas pedazo de chicas! La chispa de la jubilación, las más frescas del frontón. Es mucho mejor dos de 60 que 6 de 20, ¡vas a comparar! $»^{15}$. El actor Anjel Alkain ha interpretado en varias ocasiones a personajes femeninos como cómico televisivo, pero Maikrux ha sido el que más recorrido y éxito ha tenido. En la cultura en lengua vasca durante todo el siglo XX han existido posiciones de género y sexualidad que se pueden «in between», borrosas o trans si se quiere, mayoritariamente éstas han contribuido a regular y normalizar las normas sociales de género ${ }^{16}$; es en el cambio de siglo cuando se ha recurrido asiduamente a personajes femeninos encarnados por cis-hombres ${ }^{17}$ con los que se ha abierto la posibilidad de transgresión.

Si nos fijamos ahora en Falete, o Rafael Ojeda Rojas como consta en su documentación oficial, a pesar de sus cinco discos de copla y flamenco ${ }^{18}$ y ser hijo de uno de los Cantores de Hispalis, su popularidad está más asociada a su participación en programas de televisión. Sobre todo es conocido por los chistes recurrentes que se hacen sobre él, su aspecto y el relato de su vida sentimental en los medios de comunicación. Falete abría su monólogo en el programa Club de la Comedia, de La Sexta, el pasado 18 de julio de 2014, diciendo: «Soy cantante de flamenco y copla. Probablemente en estos últimos años sea el personaje sobre el que más chistes y parodias se hayan hecho». Hablaba abiertamente de este tratamiento humorístico, que nos remite al proceso de «espectacularización» que vive, por el cual los medios de comunicación ofrecen representaciones y contenidos sobre Falete que tienen por objeto producir entretenimiento a costa de subrayar aquellos

15. <https://www.youtube.com/watch?v=QqT3oCY4Opg> (consultado el 8-09-2014).

16. ÁlvAREZ-URIA, Amaia. «Euskal trans literarioak. Trans ezkutuen kartografia bat XX. mendeko euskal literaturan», en Isa Castillo y Iratxe Retolaza (eds.): Genero ariketak. Feminismoaren subjektuak, San Sebastián, EDO!, 2013, p. 140.

17. El prefijo «cis» significa «junto a», «el mismo que». Recientemente se ha empezado a usar este prefijo para denominar a las personas que no son trans (prefijo que significa enfrente de, ir más allá), son aquellas personas para las cuales coinciden la identidad de género, su expresión de género y el sexo asignado en el nacimiento con las expectativas tradicionales sobre cómo han de ser los hombres y las mujeres.

18. Su discografía se compone de los siguientes álbumes: Amar duele (2004), Puta mentira (2006), Coplas que nos han matao (2007), ¿Quién te crees tú? (2008) y Sin censura (2012) 
aspectos más controvertidos de su vida. Las cuestiones más cotidianas de su vida se convierten en parte del menú de la parrilla televisiva, son productos mediáticos sobre cuestiones que para otros son incluso tediosas, como aprender a conducir por ejemplo (que fue objeto del programa Famosos al $\left.V_{\text {Volante }}^{19}\right)$. No se puede decir que Falete no sea consciente de tal proceso: «Ustedes no se pueden imaginar lo difícil que es ser Falete. Sí, Falete, el de los chistes de Falete», como afirmaba en el Club de la Comedia, una espectacularización que le reporta popularidad y difusión, ya que «yo no duermo, me voy directamente a publicidad», ya que «hay artistas a los que resulta muy difícil salir en la tele, y para mí, lo más difícil es no salir» ${ }^{20}$. Estas y otras declaraciones en relación a su persona nos muestran un Falete que no es una «victima de los medios», sino más bien, alguien que utiliza el humor como forma resistencia desde un cuerpo disidente, tanto por su feminidad masculina como por su discapacidad (en sus palabras: «tengo un 'brazo de trapo' por culpa de una parálisis braquial ${ }^{21}$ ). Su sexualidad está siempre presente en las entrevistas, donde se evidencia la necesidad de los medios de fijar su identidad de género, frente a lo cual Falete responde con ciertos recursos que tienen que ver con la resistencia, como es la hipervisibilidad, como se ve en esta entrevista:

Así que un día que mi madre estaba haciendo gazpacho en la cocina con el cuchillo en la mano, tendría yo 13 años, le dije: «Mamá, me gustan los hombres», y ella me dijo, con el cuchillo apuntándome: «¿Qué hago, te mato?», pero desde el principio me apoyó, y me dijo que tenía que respetar a todo el mundo para ser respetado(...) Así que tuve la infancia, y sobre todo la adolescencia, más feliz del mundo. Un poquito cabra loca, eso sí, porque hacía cosas que no tenían pies ni cabeza, pero con el tiempo fui viendo que podía vivir de esto, de cantar, y que la gente me aceptaba sin tener que aparentar, sin esconderme, ni pensar que soy más de lo que soy, un artista. El mariquita gracioso, no; iyo soy artista! Y maricón después. Maricón suena a bóveda. Gay suena muy light. Y yo soy muy intenso para todo ${ }^{22}$.

19. Falete participó en el programa Famosos al Volante, de La Sexta, el 4 de mayo de 2012.

20. Falete en el programa Club de la Comedia, de La Sexta, emitido el 18 de julio de 2014.

21. Splash! Famosos al agua, programa de Antena 3, emitido el 4 de marzo de 2012.

22. Mora, Miguel. «Universo Falete». El País (13-03-1999). <http://elpais.com/diario/2005/03/13/eps/1110698813_850215.html > (consultado el 13-09-2014).

Feminismo/s 24, diciembre 2014, pp. 143-162 


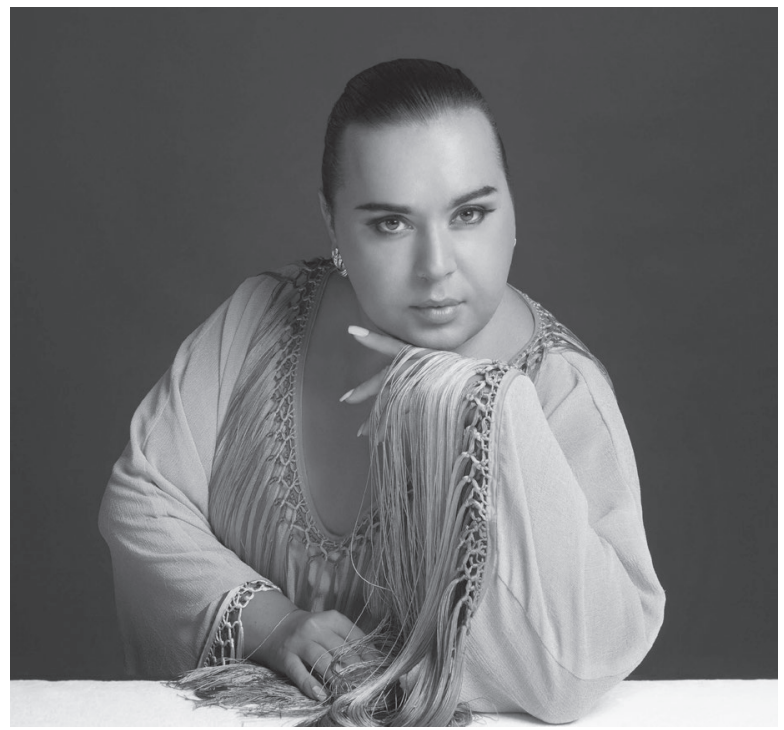

Foto 2. Foto de Falete en su web oficial. Ver http://www.faleteoficial.com

No sólo la reapropiación queer del insulto y la hipervisibilidad evitan la posibilidad de ser atacado como homosexual (ya nadie le puede llamar maricón, ya que él mismo lo hace), también desplazan el humor y la injuria hacia su aspecto, donde los medios producen chistes y hablan de su ropa, su feminidad, su peso, entre otras cuestiones. El propio Falete participa de este desplazamiento, señalando que su chiste favorito es éste: «Tienes más peligro que Falete en un buffet libre». Además, los medios dan visibilidad a comentarios que le señalan como sujeto no deseable, como éste: «Falete usa brujería para atraer a los hombres, sin importar si son gays o heteros», en palabras de su ex Isaac en un programa de televisión de $2009^{23}$, desdeñando que es protagonista de éxito de todos los programas en los que participa. Por otra parte, además de la hipervisibilidad, Falete también recurre a singularizar su forma de encarnar el «estilo de la carne», saliéndose de la lógica binaria, afirmando: «No soy ni hombre ni mujer, soy Falete», o «Lo que yo llevo no es ni de hombre ni de mujer; es de Falete», haciendo referencia a la ropa que diseña para sí mismo. Falete está atravesado por procesos de hipervisibilidad, que evidencian su feminidad encarnada en un cuerpo de cis-varón del que por otra parte se

23. VIÑAU ENA, Nacho. «Supuestamente, Falete embruja a los heteros y los convierte en gays». <http://www.ambienteg.com/curiosidades/supuestamente-falete-embruja-a-losheteros-y-los-concierte-en-gays/> publicado el 11-08-2009 (consultado el 12-09-2014). 
hacen chistes sobre su sobrepeso, y al mismo tiempo, se produce cierta invisibilidad de su diversidad funcional, que sólo es conocida para el gran público tras participar en el programa de televisión Splash! ${ }^{24}$, como ya apuntábamos.

\section{Humor y «estilo de la carne» en la televisión}

La función crítica del humor posibilita, dentro de los límites que le impone un medio comercial como la televisión, representar posturas conservadoras que reafirman el status quo al tiempo que crear fisuras en el mismo. Asimismo, el travestismo y las rupturas con los límites del género tradicional, como las que encarnan Maikrux y Falete, exponen y desafían las identidades estables, poniendo en crisis las categorías férreas de género (Garber 1997)25. Maikrux encarna o puede encarnar, las dos caras mencionadas: la de un personaje familiar y cercano que reproduce el discurso hegemónico de la cultura vasca tradicional y la que se muestra como un cis-hombre travestido ${ }^{26}$, a quien le gusta «vestirse de mujer» y "provocar al personal». Por otra parte, Falete muestra una feminidad singular, una repetición sin original, que juega con las nociones normativas de señora y flamenca, al tiempo que se mofa de tal señalamiento. Contaba jocosamente que alguien le había dicho: «¿Tiene hora, señora?» A lo que respondía: ¿Señora a mí? Con lo joven que yo soy» ${ }^{27}$. El humor que despliegan Maikrux y Falete atenúan la posible discriminación que pudieran recibir, un fenómeno que invita a la necesidad de un análisis crítico de lo cómico ${ }^{28}$. Maikrux y Falete encarnan y provocan la risa y, al mismo tiempo, traspasan lo prohibido, lo censurado, lo tabú; el humor es un espacio privilegiado donde se produce el imaginario cultural $^{29}$. No hay que olvidar que la risa es un hecho social construido en cada cultura, según parámetros de género, clase, raza, edad u otras diferencias interseccionales cruciales. El humor y la risa aluden a sistemas simbólicos con los que cada cultura imagina su existencia, donde el humor sirve para la afirmación y para la subversión

24. SPLASH! FAMOSOS AL AGUA, Ibíd.

25. GARBER, Marjorie. Vested interests. Cross-Dressing and cultural anxiety. New York, Routledge, 1997.

26. Ver nota 16.

27. EL CLUB DE LA COMEDIA, Ibíd.

28. Horlacher, Stefan. «A short introduction to theories of humour, the comic and laughter» en Gaby Pailer; Andreas Böhn; Stefan Horlacher y Ulrich Scheck (eds.): Gender and laughter. Comic affirmation and subversionin traditional and modern media. Amsterdam, Rodopi, 2009.

29. ibídem.

Feminismo/s 24, diciembre 2014, pp. 143-162 
de las identidades, al usar los roles, las relaciones y las jerarquías de género ${ }^{30}$. También es cierto que en las interacciones sociales, la risa a menudo funciona como un instrumento de poder ${ }^{31}$; si alguien amenaza con transgredir las normas, la sociedad usará la risa para su resocialización y reintegración ${ }^{32}$. La risa también opera como un indicador de las tensiones y contradicciones en una sociedad y permite analizar críticamente situaciones y mecanismos sociales, tales como los límites de la normalidad, del cuerpo o el binarismo de género, por los que son aludidos Falete y Maikrux.

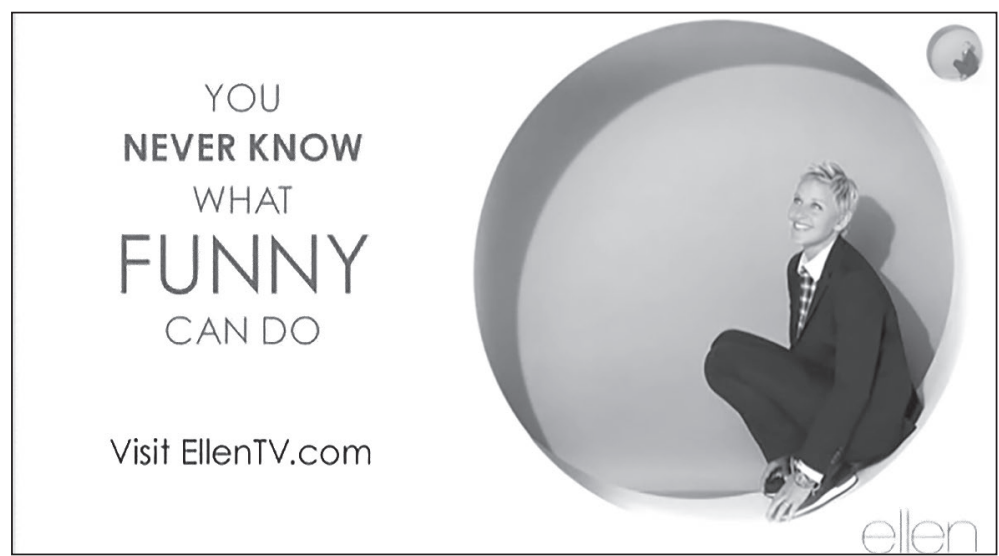

Foto 3. Foto promocional del «Show de Ellen», un programa norteamericano actual de entrevistas, protagonizado por la comediante Ellen Degeneres, famosa por haber salido del armario como lesbiana y que goza de gran popularidad. El eslógan que utiliza su programa es «You never know what funny can do» (No sabes lo que se puede conseguir siendo graciosa).

El humor libera del miedo y la censura, ataca a la ideología oficial y pone en valor la cultura popular, tal y como argumentaba Bakhtin en $1968^{33}$ y puede poner en peligro el orden establecido, al ofrecer al público el control de la situación y romper así las jerarquías y la unidireccionalidad. Lo que va en

30. BÖHN, Andreas. «Subversions of gender identities through laughter and the comic? en Gaby Pailer; Andreas Böhn; Stefan Horlacher y Ulrich Scheck (eds.): Gender and laughter. Comic affirmation and subversionin traditional and modern media. Amsterdam, Rodopi, 2009.

31. PAILER, Gaby; BÖHn, Andreas; HORLACHER, Stefan y SCHECK, Ulrich (eds.). Gender and laughter. Comic affirmation and subversionin traditional and modern media. Amsterdam, Rodopi, 2009.

32. Ibíd.

33. Ibíd.

Feminismo/s 24, diciembre 2014, pp. 143-162 
contra del comportamiento socialmente aceptado nos produce risa, como una señora hablando de «temas picantes» o Falete en bañador de volantes saltando a una piscina; esta risa puede ser un mecanismo de defensa frente a lo que tenemos como «normal» o tomamos por costumbre ${ }^{34}$, o bien, puede ser una muestra de complicidad. En este sentido Maikrux, al trasgredir el comportamiento modoso y asexual que se atribuye a las señoras vascas, está casi más cerca del estereotipo del travesti. El travesti juega intencionalmente con los roles, es el ejemplo clásico de la performatividad de género y de contrapoder o contrahegemonía, encarnando las resistencias frente al discurso hegemónico, al tiempo que puede reproducir tentativa e imperfectamente tal discurso. Marjorie Garber muestra el asombro que ha despertado el travesti a lo largo de la historia así como el poder que tiene el transgénero ${ }^{35}$, donde lo trans y el cross-dressing cuestionan directamente la categoría de género, la delimitación de lo femenino y lo masculino. Y por ende, desafían el pensamiento binarista, provocando una "crisis de las categorías» y desestabilizando las simetrías, las complementariedades y el control sobre lo conocido:

One of the most consistent and effective functions of the transvestite in culture is to indicate the place of what I call 'category crisis' (...) the extraordinary power of transvestism to disrupt, expose and challenge, putting in question the very notion of the 'original' and of stable identity (...) 'category crisis': a failure of definitional distinction, a borderline that becomes permeable, that permits of border crossings from one (apparently distinct) category to another: black/with, Jew/Christian, noble/bourgeois, master/servant, master/ slave. The binarism male/female, one apparent ground of distinction (...) is itself put in question or under erasure in transvestism, and a transvestite figure, or a transvestite mode, will always function as a sign of overdetermination -a mechanism of displacement from one blurred boundary to another ${ }^{36}$.

El travestismo se ha usado en el humor en periodos históricos en los que la forma y el contenido se correspondían estrictamente, tanto en el arte como en la vida social, donde el detonante cómico se produce por la incongruencia entre lo esperado/conocido. El juego de sorpresas y revelaciones es inherente en el cross-dressing y en el cambio de roles de género, pero ¿nos reímos con o de Maikrux y Falete? Reírse de alguien aludiría a la denigración, una sanción por romper una norma mientras que reírse con supone una identificación con el sujeto transgresor. Por eso, planteamos ¿con quién y de quién nos reímos

34. ÁLVAREZ-LÓPEZ, Sonia. «Functions and strategies of male humour in cross-gender interactions». Estudios de Sociolingüistica: Linguas, Sociedades e Culturas 3-4:2-1 (2002), pp. 173-205.

35. GARBER, Marjorie, op cit.

36. GARBER, Marjorie. Op. cit. p. 16.

Feminismo/s 24, diciembre 2014, pp. 143-162 
en los chistes de Falete («Tengo más presión que los tacones de Falete»)? ¿al deseo de quién apela Maikrux cuando dice del revisor del tren «iQué guapo! Está como para sentir picores, eh? $»^{37}$. Podría parecer a primera vista que son comentarios que refuerzan la «gordofobia» o la heterosexualidad obligatoria, pero aluden a cierto uso de un «mundo al revés» (nadie es lo que parecía a priori), que puede incitar a plantear la inestabilidad de identidades y relaciones.

Por otra parte, la televisión y los medios de comunicación donde aparecen Maikrux y Falete son espacios socioculturales de transmisión y producción de información, donde se producen representaciones y construyen valores, formas de vida, creencias, roles y significados. La TV influye en las subjetividades contemporáneas, al construir y transmitir discursos para ser, sentir y pensar, donde los sujetos tienen identificaciones y fantasías más fluidas o inesperadas de lo que se ha pensado a priori desde el feminismo. En consecuencia, ¿cómo se ha de valorar desde un punto de vista feminista y queer el éxito de audiencia y popularidad de Maikrux y Falete? Recordemos que Maikrux ha sido parte de dos programas populares y exitosos de la ETBl y que el salto de Falete en Splash! tuvo una cuota de pantalla del 41,4\% con 5,4 millones de espectadores. Si bien una de las tácticas típicas para socavar a las mujeres es usar la confusión, el humor y la ridiculización de las representaciones comunes y tópicas sobre sus roles ${ }^{38}$, en el caso de Maikrux o Falete más que generar injurias y probablemente sin que sea una apuesta consciente, los medios están evidenciando la falta de «naturalidad» que tiene la feminidad y así su carácter performativo. Asimismo, la edad también influye en la (re)clasificación en las normas de género, ya que las señoras «a cierta edad» tienen mayor libertad para dar rienda suelta al humor ${ }^{39}$, lo que facilita que Maikrux lo use en sus interacciones, invierta las relaciones de poder (re)presentando una identidad ambigua y «diferente», aunque esta trasgresión no tenga consecuencias duraderas ni cambie necesariamente las relaciones de poder ${ }^{40}$.

El estudio del humor y la agencia a través de Maikrux y Falete puede ayudar a descubrir cómo se forman las «identidades en interacción», explicitando el orden social, donde las construcciones discursivas de lo que es la

37. <https://www.youtube.com/watch? v=i2W4YR3AmNc> (consultado el 8-09-2014)

38. Valladares, Catia Elisa. Análisis del discurso de género en los programas televisivos de producción nacional dirigidos a mujeres. El Salvador, Tesis Doctoral, 2012, pp. 49-50.

39. KotTHOFF, Helga. «Gender and humor: the state of the art». Journal of Pragmatics 38 (2006), pp. 4-25.

40. CRAWFORD, Mary. «Gender and humor in social context». Journal of Pragmatics 35 (2003), pp. 1413-1430. 
masculinidad y la feminidad deben de estar situadas en su contexto cultural. En este sentido, nos preguntamos por la recepción de quienes ven la televisión en euskera y siguen Kontuz atsuak! o ven programas en los que se habla o aparece Falete. La interpretación que hacen las audiencias así como el placer que pueden sentir en las experiencias multisensoriales que producen Falete y Maikrux plantean que, al igual que como ocurre con las comedias clásicas de cross-dressing como Con faldas y a lo loco (Billy Wilder, 1959), existen posibilidades de identificación y agencia que rompen con la noción de adoctrinamiento o de identificación con un sujeto idéntico, donde ¡Nadie es perfecto!

\section{Señoras y folclóricas}

En este epígrafe abordamos las nociones de «señoras» y «folclóricas» en la medida que se han entendido habitualmente como lugares totalizantes y adoctrinadores, invisibilizando su potencial transformador y de empoderamiento. Centrándonos en el imaginario desplegado en el Estado español sobre la cultura popular folklórica y en relación al pasado reciente, Manuel Vázquez Montalbán reivindicó en Crónica sentimental de España ${ }^{41}$ la cultura popular relativa a la dictadura franquista. No en vano fue un temprano lector de Gramsci que entendió esta «subcultura» como un vehículo privilegiado de una memoria proletaria, y, concretamente de las mujeres, quienes en muchos casos fueron las portadoras de la memoria de los vencidos; tanto en sus análisis culturales como en su producción poética ${ }^{42}$, se detiene en los seriales radiofónicos, en las coplas o las canciones populares, además de en el cine, entendido como espectáculo y experiencia emocional y cotidiana. Estos medios fueron, para Vázquez Montalbán, capaces de generar una alternativa a la ideología oficial, conformando rituales colectivos, muchas veces femeninos, a partir de resignificaciones emocionales subalternas, alternativas a la ideología oficial.

Esta memoria de los parias, que se puede entender desde «la conciencia de responsabilidad memorialística» ${ }^{43}$, es la que retoma el artista José Pérez Ocaña en sus performances, cuando pasea en 1977 del brazo de Nazario por la Rambla de Barcelona al ritmo del pasodoble Francisco Alegre escrito por

41. VÁzQuez Montalbán, Manuel. Crónica sentimental de España. Barcelona, Bruguera, 1980.

42. VÁzQuez Montalbán, Manuel. Una educación sentimental; Praga. Madrid, Cátedra, 2001.

43. VeRnON, Katheen M.: «Memoria histórica y cultura popular: Vázquez Montalbán y la resistencia española», en José F. Colmeiro (coord.): Manuel Vázquez Montalbán: el compromiso con la memoria, Woodbridge, Tamesis, p. 24. 
Quintero, León y Quiroga en 1945 e interpretado por Juanita Reina ${ }^{44}$. Se está reapropiando esa cultura popular o traficando, como dice Beatriz Preciado ${ }^{45}$, con lo cursi, lo religioso, lo folklórico, lo andaluz o lo ultramarica; también se hace eco del lenguaje de los marginados. Por ello, a diferencia del planteamiento de esta filósofa, no entendemos que la cultura popular fue «cautiva» de la ideología franquista nacional-católica, sino que como ya hemos comentado, pensamos que ésta fue generalmente un espacio de posibilidad y de agencia, precisamente porque fue capaz de procurar esa recepción emocional donde las personas pudieron construir subjetividades ciertamente intactas, donde se expresaron o disfrutaron creando esos espacios de significación, físicos o virtuales, propios. Eso es lo que las mujeres vencidas, Vázquez Montalbán, Ocaña o Falete recuerdan, componiendo una particular y poderosa genealogía.

Seguramente junto con las folklóricas, otro de los tropos de significación de la cultura popular travesti o "gender queer» sea el de las «señoras». En ambos casos se conforman feminidades fuertes y empoderadas. La figura de la «señora» se suele relacionar con lo respetable, lo inofensivo, lo recatado, entre lo asexuado y lo hipersexualizado, pues un determinado estatus de edad y carácter le otorga una mayor permisibilidad social. Sin duda, las «señoras» forman una parte muy significativa de la cultura popular que alude a la feminidad travesti, lo que ha proporcionado a las audiencias cinematográficas y televisivas una serie de referentes previos y unas estrategias concretas para su entendimiento. En relación a los mismos, el humor suele ser la estrategia que procura su normalización, pero al tiempo donde reside su capacidad de resistencia, pensemos en Mrs. Doubtfire (Chris Columbus, 1993), interpretada por Robin Williams.

Pongamos en conversación los finales de las siguientes películas: Con faldas y a lo loco (Billy Wilder, 1959), Mi querida señorita (Jaime de Armiñan, 1971) y Tootsie (Sydney Pollack, 1982). En los tres casos, los sujetos «in between» han despertado deseo en otros personajes de la película, y por extensión también lo han hecho en parte de la audiencia. Es especialmente interesante el twist final de las tres películas, pues con sugerencias que se elaboran a través del humor, la idea principal que subyace es que es en el género borroso donde reside el poder de atracción de los tres personajes protagonistas. En

44. Véase la película Ocaña, retrato intermitente (Ventura Pons, 1978).

45. PRECIADO, Beatriz: «La Ocaña que merecemos: Campceptualismo, subalternidad y políticas performativas», en Ocaña 1973-1983: acciones, actuaciones, activismo, Barcelona/ Vitoria-Gasteiz, La Virreina. Centre de la Imatge/ Centro Cultural Montehermoso Kulturunea, 2011, p. 96. 
este sentido, Falete y Maikrux tienen una genealogía en este cine de comedia, donde el éxito se enmarca en su capacidad para apelar a todo tipo de audiencias. Este lugar borroso al tiempo que hipervisible permite una identificación muy plural de las audiencias, que disfrutan de la trasgresión de forma vicaria, pudiendo señalar a Falete y a Maikrux como dos «feminidades fuertes», similar a las «femmes of power» que describe Ulrika $\mathrm{Dahl}^{46} \mathrm{O}$ «las perras» de Itziar $\mathrm{Ziga}^{47}$. También, necesariamente alude al propio gusto cultural occidental por el travestismo de los hombres que se visten de mujeres, así como a la posibilidad de entender cierta suspensión de aquellas normas que rigen nuestras vidas, si se quiere de cierto «mundo al revés», donde algunos sujetos pueden jugar con la rigidez de las normas sociales, lo cual genera una importante fascinación por parte del público.

\section{Conclusiones}

En este artículo, donde elegimos abordar a Maikrux y Falete como exponentes de sujetos trasgresores que encarnan feminidades fuertes en los medios de comunicación español y vasco, hemos apuntado brevemente a una área de investigación que si bien es notoria en los contextos anglosajones, adolece de falta de suficiente atención por los estudios feministas y queer locales. Nos referimos tanto al estudio de lo vernáculo, como también de aquello que está denostado por frívolo, efímero o popular; es un trabajo que requiere de una voluntad por valorar lo cotidiano y aquello que se puede entender como relativo a la «sociología ordinaria» ${ }^{48}$, perteneciente a la cultura popular o los estudios específicos sobre la televisión y el humor. En este sentido, cabe señalar que abundan estudios anglosajones sobre figuras mediáticas como RuPaul ${ }^{49} \mathrm{O}$ sobre las series de televisión como L-word ${ }^{50}$ o Queer as Folk ${ }^{51}$; por el contrario, el vacío es total si abordamos la presencia de Falete o Maikrux u otras figuras

46. VolCANO, Del LaGrace y DAHL, Ulrika. Femmes of power. Exploding Queer Femininities. London, Serpent's Tail, 2008.

47. ZIGA, Itziar. Devenir perra. Barcelona, Melusina, 2009.

48. Ver por ejemplo el trabajo que desarrollan Amparo Lasén y Elena Casado sobre la sociología ordinaria en <http://sociologiaordinaria.com> (consultado el 12-09-2014).

49. Drag queen, modelo y compositor norteamericana que ha participado en numerosos programas y películas de éxito desde los año 90.

50. Ha sido la primera serie norteamericana de éxito que aborda el lesbianismo, que fue dirigida por Ilene Chaiken y emitida entre 2004-2008 por la cadena Showtime. En el Estado español se tradujo por «L» (de lesbiana) y fue emitida por Canal+.

51. Esta serie británica que aborda la vida de un grupo de gays de clase media fue volvió a filmar en Estados Unidos y Canadá, siendo producida por Showtime y Temple St. Productions, alcanzando gran éxito en su emisión entre 2000 y 2005. En el Estado español se emitió entre 2006 y 2007 en Cuatro.

Feminismo/s 24, diciembre 2014, pp. 143-162 
transgresoras locales. A través de nuestra reflexión también hemos apuntado hacia la importancia de la recepción, a la necesidad de cierto giro gramsciano presente en los estudios culturales para entender que no siempre la cultura popular provoca procesos totalizadores y adoctrinantes, sino que como apunta Labanyi, las audiencias negocian según sus propios intereses gracias a su capacidad de apropiación, subjetiva y generalmente empoderadora.

Maikrux y Falete utilizan el humor para poder ser, participando en la construcción de su presencia mediática, al tiempo que juegan con los límites de lo real y la ficción, así como de lo público y lo privado, poniendo en cuestión estas clasificaciones binarias. Maikrux y Falete encarnan cierta «gestión» de lo normativo y lo transgresor, donde no son necesariamente víctimas ni sujetos pasivos, lo cual dificulta su fácil adscripción a una mirada binaria sobre si refuerzan o trasgreden los binarismos de género o sobre la sexualidad. El estudio de su lugar como sujetos que están en la encrucijada de lo queer, las señoras, lo folklórico, la cultura vasca y lo crip $^{52}$ requiere de marcos de análisis radicales, propios de los estudios decoloniales, queer, postfeministas, críticos con diversidad funcional y el antirracismo. En este sentido, nuestro trabajo sobre Falete y Maikrux pretende emparentarse con un ámbito internacional de estudio que valora el aporte de estas figuras a la configuración del imaginario social y cultural local y global, subrayando su importancia como parte del legado y la genealogía de los subalternos. El estudio de Falete y Maikrux requiere marcos de interpretación que devengan en análisis complejos, excediendo la lógica binaria de si transgreden o subrayan las normas más convencionales sobre los géneros, si son o no son queers, si los medios de comunicación los utilizan de forma espectacular para vender «risas» o, si por el contrario, su sentido del humor es una arma arrojadiza que nos enfrenta con nuestras contradicciones, evidenciando lo artificial de nuestras normas sociales. «Nadie es perfecto», ni siquiera Falete y Maikrux.

52. Literalmente «crip» es una expresión coloquial ofensiva que se usa para designar a una persona que tiene una discapacidad y no puede servirse de algunos de sus miembros. También es un movimiento social crítico de las personas con diversidad funcional que luchan contra la noción de normalidad, revelándose contra la obligatoriedad de tener un cuerpo perfecto según los cánones vigentes, un estándar sobre la inteligencia, sobre los comportamientos sexuales, sociales o culturales, entre otros. Véase PLATERO, Raquel (Lucas) y Rosón María. «De 'la parada de los monstruos' a los monstruos de lo cotidiano: La diversidad funcional y sexualidad no normativa». Feminismo/s, 19 (2012), pp. 127-142. 


\section{Referencias bibliográficas}

ADORNo, Theodor W. y HORKHEIMER, Max: «La industria cultural. Ilustración como engaño de masas», en Dialéctica de la ilustración, Madrid, vol. 3, Akal, 2007, pp. 133-182.

ÁlVAREZ-LÓPEZ, Sonia. «Functions and strategies of male humour in cross-gender interactions». Estudios de Sociolingüistica: Linguas, Sociedades e Culturas 3-4:2-1 (2002), pp. 173-205.

ÁlvareZ-UriA, Amaia. «Euskal trans literarioak. Trans ezkutuen kartografia bat XX. mendeko euskal literaturan», en Isa Castillo y Iratxe Retolaza (eds.): Genero ariketak. Feminismoaren subjektuak. San Sebastián, EDO!, 2013, pp. 139-163.

BöHN, Andreas. «Subversions of gender identities through laughter and the comic?», en Gaby Pailer; Andreas Böhn; Stefan Horlacher y Ulrich Scheck (eds.): Gender and laughter. Comic affirmation and subversion in traditional and modern media. Amsterdam, Rodopi, 2009, pp. 49-64.

Bordieu, Pierre. La distinción. Criterio y bases sociales del gusto. Madrid, Taurus, 1998.

BUTLER, Judith. El género en disputa. El feminismo y la subversión de la identidad. Barcelona, Paidós, 2007.

Clough, Patricia (ed.). The Affective Turn: Theorizing the Social. Durham, Duke University Press, 2007.

CRAWFORD, Mary. «Gender and humor in social context». Journal of Pragmatics 35 (2003), pp. 1413-1430.

ETXEBERRIA, Idoia. «Earki gatxink!». Berria (27-01-2006), pp. s 4-5.

GARBER, Marjorie. Vested Interests. Cross-Dressing and Cultural Anxiety. New York, Routledge, 1997.

HORLACHER, Stefan. «A short introduction to theories of humour, the comic and laughter», en Gaby Pailer; Andreas Böhn; Stefan Horlacher y Ulrich Scheck (eds.): Gender and laughter. Comic affirmation and subversion in traditional and modern media. Amsterdam, Rodopi, 2009, pp. 17-47.

KotThofF, Helga. «Gender and humor: The state of the art». Journal of Pragmatics 38 (2006), pp. 4-25.

LabanYI, Jo. «Gramsci and the Spanish Cultural Studies». Paragraph 22/1 (1999), pp. 95-113.

LABANYI, Jo. «Música, populismo y hegemonía en el cine del primer franquismo», en Luis Fernández Colorado y Pilar Couto Cantero (eds.): Cuadernos de la Academia. La herida de las sombras. El cine español de los años 40, núm. 9, 2001, pp. 83-97.

LAKUNZA, Rosana. «Hay programas donde no hay intención de innovar: son demasiado cuadrados». Deia (19-09-2011), p. 66. 
LASA, Iñaki. «Bizitzak ba al du zentzurik barrerik egin gabe ba?». Berria (06-012013), p. 36.

LÓPEZ, Elisa. «¿Hacer de mujer? Pues sí, a los hombres nos gusta». Diario Vasco (09-10-2011), p. 82.

Medina Domenech, Rosa María. «Sentir la Historia. Propuestas para una agenda de investigación feminista en la historia de las emociones». Arenal. Revista de Historia de las Mujeres 19/1 (2012), pp. 161-199.

MitXelenA, Eñaut. «Herriak behar gaitu, bestela ez gintuzten hainbeste maiteko». Aizu! 376 (Abril de 2013), pp. 30-33.

MorA, Miguel. «Universo Falete». El País, (13-03-1999), <http://elpais.com/diario/2005/03/13/eps/1110698813_850215.html > (consultado el 13-09-2014)

NORRICK, Neal R. y CHIARO, Delia. (eds.). Humor in interaction. Amsterdam, Benjamins, 2009.

PAiler, Gaby; BÖHN, Andreas; Horlacher, Stefan y SCHECK, Ulrich (eds.). Gender and laughter. Comic affirmation and subversion in traditional and modern media. Amsterdam, Rodopi, 2009. Págs. 49-64.

Platero, Raquel (Lucas) y Rosón María. «De 'la parada de los monstruos' a los monstruos de lo cotidiano: La diversidad funcional y sexualidad no normativa». Feminismo/s, 19 (2012), pp. 127-142.

PRECIADO, Beatriz: «La Ocaña que merecemos: Campceptualismo, subalternidad y políticas performativas», en Ocaña 1973-1983: acciones, actuaciones, activismo, Barcelona/Vitoria-Gasteiz, La Virreina. Centre de la Imatge/ Centro Cultural Montehermoso Kulturunea, 2011, pp. 72-169.

UrkizU, Urtzi. «'Finlandia' saioa desagertu ostean, 'Kontuz atsuak!' helduko da ETBlera». Berria (10-07-2012), p. 28.

Valladares, Catia.Elisa. Análisis del discurso de género en los programas televisivos de producción nacional dirigidos a mujeres (Tesis Doctoral). El Salvador, 2012.

VÁzQuez Montalbán, Manuel. Crónica sentimental de España. Barcelona, Bruguera, 1980.

VÁzQuez Montalbán, Manuel. Una educación sentimental. Praga, Madrid, Cátedra, 2001.

VERNON, Katheen M.: «Memoria histórica y cultura popular: Vázquez Montalbán y la resistencia española», en José F. Colmeiro (coord.): Manuel Vázquez Montalbán: el compromiso con la memoria, Woodbridge, Tamesis, 2007, pp. 21-34.

VIÑAU ENA, Nacho. «Supuestamente, Falete embruja a los heteros y los convierte en gays». <http://www.ambienteg.com/curiosidades/supuestamente-faleteembruja-a-los-heteros-y-los-concierte-en-gays/> publicado el 11-08-2009 (consultado el 12-09-2014).

VolCANO, Del LaGrace y DAHL, Ulrika. Femmes of power. Exploding Queer Femininities. London, Serpent's Tail, 2008.

ZIGA, Itziar. Devenir perra. Barcelona, Melusina, 2009. 